\title{
Yield Reduction Caused by Twospotted Spider Mite Feeding in an Advanced-cycle Strawberry Breeding Population
}

\author{
Douglas B. Walsh \\ Department of Entomology, Washington State University, Prosser, WA 99350 \\ Frank G. Zalom \\ Department of Entomology, University of California, Davis, CA 95616 \\ Douglas V. Shaw and Kirk D. Larson \\ Department of Pomology, University of California, Davis, CA 95616
}

ADDITIONAL INDEX wORDS. Tetranychus urticae, Fragaria $\times$ ananassa, genotypes, host plant resistance

\begin{abstract}
Forty-eight strawberry (Fragaria $\times$ ananassa Duchesne) or (Fragaria L. sp.) genotypes from the University of California advanced-cycle breeding population were evaluated over 7 years for susceptibility to and tolerance of infestation by two-spotted spider mite (Tetranychus urticae Koch). In pairwise tests, 23 photoperiodically short-day genotypes were compared with the short-day cultivar Chandler, and 23 day-neutral genotypes to the day-neutral cultivar Selva. Feeding by $\boldsymbol{T}$. urticae resulted in substantial yield reductions regardless of genotype. Yield reduction from feeding by $\boldsymbol{T}$. urticae averaged $29.9 \%$ for short-day and $23 \%$ for day-neutral genotypes. Calculation of variance components for day-neutral genotypes determined that none of the variation in yield was explained by the interaction of genotype and $T$. urticae infestation, whereas $\mathbf{2 4 . 4 \%}$ of the variation in yield for short-day genotypes was explained by the interaction of genotype and $T$. urticae infestation. Under current strawberry production practices in California there appears to be little potential for breeding direct resistance to $T$. urticae for day-neutral genotypes. However, some gains in breeding direct $\boldsymbol{T}$. urticae resistance may be achieved within short-day genotypes. Phenotypic path-coefficient analysis for direct and indirect effects, and simple correlation coefficients of $T$. urticae feeding determined there were substantial differences between short-day and day-neutral genotypes in their yield responses to $T$. urticae feeding. For short-day genotypes, the greatest direct effect on yield resulted from $T$. urticae feeding in June. For day-neutral genotypes, the greatest direct effects resulted from $T$. urticae feeding in April and May and were probably due to the day-neutral genotype's more complex flowering responses. Several high-yielding cultivars have been developed and released over the 7 years of this study. It appears the new cultivars that were bred for current cultural practices exhibited a consistent plant response for greater yield both in the presence and absence of $T$. urticae feeding.
\end{abstract}

University of California strawberry cultivars are adaptable to many climates and are grown worldwide. Currently, they account for the majority of Western Hemisphere strawberries produced for fresh-market delivery and a large portion produced for the processing market (Galletta and Bringhurst, 1990). The twospotted spider mite, Tetranychus urticae (Acari: Tetranychidae), is a perennial and omnipresent arthropod pest of commercial strawberries, in California (Zalom et al., 1990) and other strawberryproducing regions (Shanks, 1980). In California, $>99 \%$ of the hectares are treated with at least one acaricide application and 95\% are treated two or more times with acaricide applications to prevent or suppress $T$. urticae infestations (California Department of Pesticide Regulation, 1999).

Several attempts have been made to discover mite-resistant strawberry genotypes and then incorporate the observed traits for resistance into commercial germplasm (Barritt, 1980; Hancock et al., 1991; Gimenez-Ferrer et al., 1993; Shanks and Moore, 1995). Most studies of mite resistance on strawberry plants have involved estimating mite abundance or rating foliar damage or physiological response to determine differences in susceptibility to mite infestation or tolerance of mite feeding among genotypes.

Received for publication 21 May 1999. Accepted for publication 13 Nov. 2001. Funding for this project was provided by the California Strawberry Commission. We thank Harry Kaya and the late Sean S. Duffey for reviews of the manuscript and Norman Welch, Delores Rodriguez, Larry Fulton, John Hansen, Sean Fort, and June Trimble for technical assistance with these experiments.
Few studies have incorporated the critical economic component of yield reduction resulting from feeding by $T$. urticae as a criterion for evaluating mite resistance among strawberry genotypes.

Climate and other environmental conditions affect strawberry plant growth and reproductive status, and these factors were reviewed by Larson (1994). Wild-type Fragaria sp. respond to the environment by allocating photosynthetic assimilate resources differentially to vegetative growth, vegetative reproduction, or sexual reproduction (Jurik, 1985). The intensity of strawberry culture in California is designed to remove biotic competition, minimize abiotic stress, and maximize resource availability to promote timely and high-volume fruit production. Market forces dominant cultivar selection and the cultivar chosen will in turn determine cultural practices (Galletta and Bringhurst, 1990).

Modern commercial strawberry cultivars can be classified into two groups depending on their reproductive and vegetative responses to daylength. Most strawberries (domestic and wild types) are classified as short-day. This type of floral induction generally occurs with photoperiods $<14 \mathrm{~h}$. The second photoperiodic group of strawberries is comprised of day-neutral cultivars that will generally flower in cool-summer Mediterranean climates regardless of daylength.

Most southern California (San Diego, Orange, Los Angeles, and Ventura counties) strawberry producers plant short-day cultivars. Fruit production plantations in southern California are established in early to mid-October. Planting stock is comprised 
of runner plants that are propagated asexually in high-elevation $(>1,200 \mathrm{~m})$ nursery fields in northeastern California or southeastern Oregon. The plants in nursery fields are machine harvested, trimmed to crown and root, boxed, and then shipped by refrigerated truck to southern California. Time from plant harvest at the nursery to transplant in the production plantation takes 2 or $3 \mathrm{~d}$. These and other cultural practices are contrived to force the plants to produce fresh market fruit for a market window in middle to late winter and early spring when other fresh fruits are in short supply and fresh strawberries can command a premium economic return. Fruit produced in southern California in late spring are used primarily for processing at a substantially reduced economic return (Galletta and Bringhurst, 1990). Southern California strawberry producers usually terminate fruit harvest by late spring or early summer.

Alternatively, the cultural system of strawberry producers in the Monterey Bay region of central California (Santa Cruz and Monterey counties) relies primarily on the November transplant of day-neutral cultivars. Day-neutral transplants are harvested from nurseries somewhat later (1 to 3 weeks) than short-day cultivars. Most strawberry producers store the boxed, day-neutral bare-root transplants in hydrocoolers for 1 to 4 weeks at temperatures just above freezing, before transplant in November, to promote a plant vigor response (Voth and Bringhurst, 1970). Commercial harvest will commence in mid-spring and will continue throughout summer and into late fall. Cultural practices and cultivar selection of south central California coast producers (Santa Barbara and San Luis Obispo counties) are intermediate and more varied than those used by producers to either the north or south. However, the photoperiodicity of the cultivar selected will determine which of the two cultural and harvest systems producers will follow.

Natural and artificial chilling below $7.2^{\circ} \mathrm{C}$ in nursery fields during fall, in cold storage, or in the production plantation during fall and winter will impact plant vigor during spring (Voth and Bringhurst, 1970). Low plant vigor has been associated with increased plant susceptibility to infestation by $T$. urticae, whereas high plant vigor has been associated with a delay of infestation by T. urticae (Walsh et al. 1997). Strawberry producers strive to achieve a balance between vegetative and reproductive growth (Welch et al. 1990), and most cultural practices are designed to fulfill this objective. Day-neutral genotypes usually require more plant chilling than short-day genotypes to promote an adequate plant vigor response.

The objective of this study was to determine quantitative relationships between $T$. urticae infestation and yield reduction caused by $T$. urticae feeding in the University of California advanced cycle strawberry breeding population. We evaluated 48 genotypes from this population over 7 years for susceptibility to and tolerance of $T$. urticae infestation and calculated the yield reduction resulting from $T$. urticae feeding on each genotype tested within each year. Additionally, we attempted to measure the level of genetic variation of tolerance to $T$. urticae feeding among the tested genotypes. Finally, the relationship between $T$. urticae population density, the temporal period of $T$. urticae feeding, and strawberry fruit yield were examined by correlation analysis.

\section{Materials and Methods}

Pairwise comparisons tests, 1988 Through 1996. Field trials were established annually each fall from 1988 through 1995, at the University of California Strawberry Research Facility near Watsonville, in the central coast of California (lat. 36E 54' N, long. $121 \mathrm{E} 48^{\prime} \mathrm{W}$ ) by transplanting selected bareroot strawberry runner plants that were harvested on 15 Oct. of each year from a high-elevation $(1,300 \mathrm{~m})$ strawberry nursery in Macdoel, Calif. (lat. 41E 45'N, long. 121E 59'W).

Twenty-five day-neutral and 23 short-day genotypes with a range of production patterns were tested over the course of these studies. Of these genotypes, 15 were tested two or more years. The 48 genotypes were chosen from the University of California strawberry improvement program. Twenty-one of the genotypes tested have been released as cultivar selections before, during, or after the completion of this study. 'Chandler' and 'Selva' were, respectively, the industry standard short-day and day-neutral cultivars for all 7 years of this study. Since these studies were a part of the University of California strawberry genetic improvement program, all genotypes were compared categorically to 'Chandler' or 'Selva' according to the photoperiodic reproductive response of each genotype.

Photoperiodically short-day and day-neutral genotypes were stored for 1 and 4 weeks, respectively, in a hydrocooler at $0.5^{\circ} \mathrm{C}$ to increase plant vigor by promoting a chilling response before transplanting into the production plantation. Following standard commercial production practices (Welch, 1990), plots were established on methyl bromide-chloropicrin fumigated, prefertilized, two-row diagonal raised beds with $132-\mathrm{cm}$ centers and $34-\mathrm{cm}$ plant spacing along rows (39,540 plants/ha).

Paired plots of 20 plants each were established for each genotype represented in a year. Two replicates were treated with acaricides to prevent $T$. urticae infestation whereas two replicates remained nontreated with acaricides. Acaricide treatment regimes varied slightly among years depending on variability of $T$. urticae abundance. However, the treated plots received on average two to three applications of abamectin (Agrimek 0.15 EC; Syngenta Corp, Greensboro, N.C.), at a rate of $0.02 \mathrm{~kg}$ a.i./acre (0.4 ha). All other cultural practices were identical. Tetranychus urticae density was determined on plants in the nontreated plots by harvesting 10 mid-tier leaflets per replicate every 2 weeks, transporting the leaves to the laboratory, and mite brushing and counting mites present on the leaves (Henderson and McBurnie, 1954). Mite-days (Andrews and La Pre, 1979) were calculated and summed for monthly intervals for each season by using 15 Mar. and 30 Aug. as starting and ending dates to provide a standard index of T. urticae feeding. A hard frost in Winter 1990 injured plants and suppressed mites. Results from experiments conducted in that year were considered unreliable and not considered further. Ripe fruit from the plots were harvested weekly from April through August, and from those harvests, annual yields were calculated as grams of fruit produced per plant. Average fruit weight was determined by averaging the weights of 10 randomly chosen fruit per replicate on each harvest date. Weekly yield per plant was divided by average fruit size as an estimate of the number of market quality berries produced per plant per week.

All yield and $T$. urticae abundance data were analyzed using fixed effects analysis of variance (ANOVA, SAS Institute, Inc. 1990). Treatment means within years of short-day genotypes were compared with 'Chandler' and day-neutral genotypes were compared with 'Selva' in a pairwise $t$ test (Abacus Concepts, 1989). Additionally, the treatment means for total yield of the acaricide treated and nontreated plots were compared in a pairwise $t$ test by genotype to determine if $T$. urticae feeding on a genotype within a year resulted in significant percentage of yield reduction. 
Combined analysis. Variances due to year, replicate within year, genotype, mite treatment (spray), and their interactions were tested by ANOVA performed using SAS procedure GLM (SAS Inst., Inc. 1990). Components of variance for genotype, genotype by spray, and genotype by spray by year interactions were calculated for short-day and day-neutral sets of genotypes for annual yields and fruit sizes. These components were compared to evaluate the magnitude of differences among genotypes over all treatments, differences in plant responses to acaricide application, or to differences in genotypic response to the acaricide spray among years. Additionally, a similar analysis was conducted on all of the genotypes combined.

A path analysis of phenotypic correlations by plant photoperiodicity (day-neutral or short-day) was constructed in which six variables including the week mites were first detected (week one, 10 to 16 Mar.; week two, 17 to 23 Mar., etc.) and mitedays accumulated during April, May, June, July, and August were recorded, and their effects on percentage of yield reduction calculated. Path analysis permits the partitioning of the correlation coefficients between the dependant variable and the independent variables into direct and indirect effects (Li 1975, Loehlin 1987). A direct effect is called a path coefficient and is a standardized partial regression coefficient. Path coefficient analysis (Wright, 1921) was used to determine the direct and indirect phenotypic correlations between the timing and severity of $T$. urticae infestation with yield reduction. The time periods in which $T$. urticae were feeding were grouped into a relational table containing hypothesized pathways of the influence of $T$. urticae feeding on yield. Path coefficients were obtained by the simultaneous solution of the normal equations for multiple regression in standard measure.

\section{Results}

Results of ANOVA and descriptive statistics for maximum abundance of $T$. urticae per leaflet, accumulated mite-days, and fruit yield are listed in Table 1 for short-day genotypes and Table 2 for day-neutral genotypes tested in each year. In a separate analysis, each short-day or day-neutral genotype was compared within year in pairwise $t$ tests with either 'Chandler' (Table 1) or 'Selva' (Table 2), respectively. Factors compared included maximum abundance of $T$. urticae per leaflet, accumulated mite-days, and fruit yield in plots that had been treated with or remained nontreated with acaricides, Additionally, yields of each genotype treated with or without acaricides were compared within year by pairwise $t$ tests to determine if yield reduction resulting from $T$. urticae feeding within that year was significant $(P<0.05)$. Regardless of genotype, plant photoperiodicity, relative level of infestation within year, or harvest year, $T$. urticae feeding usually resulted in substantial yield reduction (Tables 1 and 2). There were significant $(P<0.05)$ differences between 'Chandler' and the other genotypes compared within year during 6 of the 7 years of this study (Table 1). 'Chandler' had greater yields than several genotypes in 1989, but in 1992, 1993, and 1995 most of the genotypes in the study had greater yields than 'Chandler' when $T$. urticae populations remained suppressed. When $T$. urticae were left uncontrolled and infestations developed, percentage of yield reduction tended to be greater on the newer genotypes than on 'Chandler'. However, a recently released (1993) short-day cultivar, Camarosa, produced higher yields than 'Chandler' in 1995 and 1996, regardless of $T$. urticae abundance. There was no clear association between yield potential and percentage of yield loss to T. urticae feeding. For example, 'Tioga', a 1953 selection, had the lowest acaricide treated and nontreated yield of genotypes tested in 1989, yet percentage of yield reduction due to T. urticae feeding was near the middle of our observations. Similar results were observed on the acaricide-treated day-neutral genotypes, with several of the newer genotypes exhibiting greater yield than 'Selva' regardless of $T$. urticae abundance. Although T. urticae feeding usually resulted in substantial yield reduction within genotype and year, there was rarely a rank shift in yield caused by mite feeding among genotypes within year. Yield reduction averaged $29.9 \%$ for short-day genotypes, and $23 \%$ for dayneutral genotypes over the 7 years of this study.

ANOVA for yield and fruit size of all genotypes combined demonstrates that acaricide treatments $(\mathrm{S})$, harvest year $(\mathrm{Y})$, and genotype $(\mathrm{G})$ had highly significant $(P<0.01)$ impact on yield and fruit size (Table 3 ). Additionally, the interactions of year $\times$ genotype, year $\times$ spray, genotype $\times$ spray, and year $\times$ genotype $\times$ spray were all highly significant $(P<0.01)$ or significant $(P<$ $0.05)$ for yield. Year $\times$ genotype was highly significant $(P<0.01)$ and year $\times$ spray was significant $(P<0.05)$ for fruit size. The genotype $\times$ spray and year $\times$ genotype $\times$ spray interactions were nonsignificant $(P>0.05)$ for fruit size. Conversely, the year $\times$ genotype $\times$ spray interaction was nonsignificant $(P>0.05)$ for either the short-day or day-neutral genotypes when data for these plant types were analyzed separately (Table 3).

Calculation of the variance components for all genotypes combined demonstrates that the majority of the variance for yield and fruit size results from differences between genotypes and is consistent across acaricide treatment, and that there is little variation in the response of genotypes to infestation by T. Urticae (Table 3). This was particularly true for day-neutral selections in which none of the variation in yield and only $1.5 \%$ of the variation in fruit size is explained by the interaction of genotype and $T$. urticae infestation (Table 3). However, in the day-neutral genotypes, $14.2 \%$ of the variance in yield is explained by the interaction of genotype and T. urticae by harvest year (Table 3 ) indicating there may be some interactions that reflect specific adaptation but that is not consistent over yearly environmental differences. This is somewhat different from the results for short-day genotypes where $75.6 \%$ of the variance is explained by genotype and $24.4 \%$ of the variance in yield is explained by the interaction of genotype and T. urticae infestation (Table 3).

Path coefficient analysis. The phenotypic path coefficients for direct and indirect effects, and simple correlation coefficients of $T$. urticae factors affecting fruit yield including week $T$. urticae were detected and monthly mite-day accumulations from April through August are shown in Table 4. Differences between short-day and day-neutral genotypes were found in accumulated mite-days, and in their yield responses to feeding by $T$. urticae in similar periods of time. For short-day genotypes, the greatest direct effect on yield resulted from mite-day accumulation in June. For day-neutral cultivars the most significant direct effect on yield resulted from mite-day accumulation during April and May, and a significant negative direct effect was observed for the week mites first became detectable. These results are consistent with our prior observation for 'Selva' (Walsh et al., 1997) that suggested early-spring mite-day accumulation resulted in greater yield loss than equivalent mite-day accumulation during late-spring or summer. Week of mite detection also had a significant indirect effect on yield via mite-day accumulation in April, May, and June due to the fact that the earlier mites were detected in late-winter or spring the greater the mite dayaccumulations were in April, May, and June. 
Table 1. ANOVA for short-day genotypes tested within year, mean and SE for maximum abundance of $T$. urticae observed per leaflet, accumulated mite-days in nonacaricide treated plots, yield in acaricide-treated and nontreated plots, and yield reduction caused by $T$. urticae feeding.

\begin{tabular}{|c|c|c|c|c|c|c|}
\hline \multirow[b]{2}{*}{ Year } & \multirow[b]{2}{*}{ Genotype } & \multirow{2}{*}{$\begin{array}{c}\text { T. urticael } \\
\text { leaflet }^{\mathrm{z}}\end{array}$} & \multirow{2}{*}{$\begin{array}{l}\text { Mite- } \\
\text { days }^{\mathrm{z}}\end{array}$} & \multicolumn{2}{|c|}{ Yield (g/plant) ${ }^{2}$} & \multirow{2}{*}{$\begin{array}{c}\text { Yield } \\
\text { reduction }(\%)\end{array}$} \\
\hline & & & & Treated & Nontreated & \\
\hline \multirow[t]{5}{*}{1989} & Mean squares & 8,311 & $4,527,331$ & $638,519^{* *}$ & $136,417^{* * *}$ & \\
\hline & Chandler & $23 \pm 2$ & $1,502 \pm 499$ & $2,237 \pm 15$ & $1,298 \pm 11$ & $41.9^{* * *}$ \\
\hline & Tioga & 134.26 & $4,956^{*} \pm 175$ & $893^{* *} \pm 92$ & $679^{* * *} \pm 102$ & 22.0 \\
\hline & $81.403-603$ & $144 \pm 68$ & $4,147^{*} \pm 1,204$ & $1,816^{* *} \pm 248$ & $905^{*} \pm 247$ & 48.8 \\
\hline & $84.8-1$ & $168 \pm 13$ & $4,128^{*} \pm 170$ & $1,519^{* * *} \pm 16$ & $1,064 \pm 15$ & $30.0^{*}$ \\
\hline \multirow[t]{3}{*}{1991} & Mean squares & 1,681 & 483,065 & $80,813^{* *}$ & 18,919 & \\
\hline & Chandler & $26 \pm 17$ & $752 \pm 405$ & $1,572 \pm 68$ & $1,274 \pm 121$ & 19.2 \\
\hline & $85.188-201$ & $71 \pm 20$ & $1,191 \pm 723$ & $1,280^{* * *} \pm 21$ & $1,057 \pm 88$ & 17.3 \\
\hline \multirow[t]{2}{*}{ Cuesta } & $57 \pm 1$ & $1,204 \pm 96$ & $1,706^{*} \pm 52$ & $1,250 \pm 51$ & $26.5^{*}$ & \\
\hline & $87.283-203$ & $8 \pm 0$ & $161 \pm 20$ & $1,332^{* *} \pm 17$ & $1,202 \pm 42$ & 9.7 \\
\hline \multirow[t]{8}{*}{1992} & Mean squares & 21,464 & $1,913,000$ & $145,404^{* *}$ & 92,975 & \\
\hline & Chandler & $78 \pm 22$ & $1,818 \pm 254$ & $1,451 \pm 209$ & $941 \pm 34$ & 34.2 \\
\hline & Cuesta & $264 \pm 154$ & $5,005 \pm 1,595$ & $1,372 \pm 13$ & $780 \pm 59$ & $43.0^{*}$ \\
\hline & $88.12-2$ & $79 \pm 22$ & $2,129 \pm 654$ & $1,730 \pm 101$ & $1,173 \pm 157$ & 32.5 \\
\hline & Camarosa & $52 \pm 8$ & $1,394 \pm 312$ & $1,759 \pm 91$ & $1,084 \pm 169$ & 37.1 \\
\hline & C-203 & $194 \pm 81$ & $4,840 \pm 2,104$ & $1,624 \pm 119$ & $887 \pm 48$ & $44.8^{*}$ \\
\hline & Carlsbad & $148 \pm 25$ & $3,992 \pm 475$ & $1,848^{*} \pm 138$ & $1,326^{*} \pm 79$ & 27.5 \\
\hline & $88.118-603$ & $49 \pm 20$ & $1,727 \pm 766$ & $2,185^{* *} \pm 65$ & $1,213 \pm 90$ & $44.3^{*}$ \\
\hline \multirow[t]{7}{*}{1993} & Mean squares & 21,464 & $1,913,000$ & $41,516^{* *}$ & 92,975 & \\
\hline & Chandler & $340 \pm 265$ & $7,682 \pm 4,997$ & $1,307 \pm 19$ & $999 \pm 171$ & 23.7 \\
\hline & Cuesta & $332 \pm 85$ & $11,651 \pm 2,342$ & $1,423^{*} \pm 50$ & $796 \pm 128$ & $43.7^{*}$ \\
\hline & $88.12-2$ & $132 \pm 34$ & $4,853 \pm 470$ & $1,381 \pm 33$ & $988 \pm 149$ & 28.7 \\
\hline & $88.12-6$ & $307 \pm 229$ & $10,750 \pm 8,632$ & $1,326 \pm 8$ & $749 \pm 100$ & $43.5^{*}$ \\
\hline & $\mathrm{C} 203$ & $202 \pm 35$ & $6,617 \pm 1,085$ & $1,604^{* *} \pm 8$ & $985 \pm 16$ & $39.0^{* * *}$ \\
\hline & $89.231-32$ & $107 \pm 38$ & $3,999 \pm 404$ & $1,647^{* *} \pm 7$ & $1,360 \pm 110$ & 17.3 \\
\hline \multirow[t]{7}{*}{1994} & Mean squares & $103,730^{* * *}$ & $7,227,000^{* * *}$ & 113,821 & 103,720 & \\
\hline & Chandler & $143 \pm 123$ & $5,831 \pm 4,982$ & $1,682 \pm 47$ & $1,318 \pm 182$ & 21.9 \\
\hline & Cuesta & $714 \pm 66^{* *}$ & $20,609^{*} \pm 1,565$ & $1,522 \pm 31$ & $876^{*} \pm 33$ & $42.4^{* *}$ \\
\hline & Camarosa & $217 \pm 16$ & $8,391 \pm 1,408$ & $2,098^{*} \pm 38$ & $1,294 \pm 163$ & $38.5^{*}$ \\
\hline & C203 & $195 \pm 45$ & $8,273 \pm 998$ & $1,730 \pm 239$ & $785 \pm 55$ & 53.3 \\
\hline & $88.66-616$ & $76 \pm 45$ & $3,176 \pm 1,751$ & $1,395 \pm 124$ & $1,189^{*} \pm 114$ & 13.3 \\
\hline & Carlsbad & $284 \pm 76$ & $10,536 \pm 1,389$ & $1,652 \pm 146$ & $1,237 \pm 46$ & 24.8 \\
\hline \multirow[t]{8}{*}{1995} & Mean squares & 3,151 & $2,182,975$ & $142,004^{* *}$ & $127,630^{*}$ & \\
\hline & Chandler & $33 \pm 2$ & $1,589 \pm 399$ & $1,314 \pm 62$ & $1,302 \pm 81$ & 0.3 \\
\hline & Camarosa & $30 \pm 21$ & $650 \pm 276$ & $1,7,89^{* *} \pm 20$ & $1,559 \pm 45$ & $12.9^{*}$ \\
\hline & C203 & $50 \pm 31$ & $1513 \pm 826$ & $1,834^{* *} \pm 31$ & $1,369 \pm 102$ & $25.2^{*}$ \\
\hline & C204 & $71 \pm 21$ & $2,476 \pm 697$ & $1,944^{* *} \pm 74$ & $1,508 \pm 114$ & 22.1 \\
\hline & Gaviota & $37 \pm 13$ & $1,555 \pm 525$ & $1,579^{*} \pm 63$ & $1,100 \pm 175$ & 29.8 \\
\hline & $91.263-1$ & $140 \pm 48^{*}$ & $3,807 \pm 2,075$ & $1,901^{* *} \pm 50$ & $1,160 \pm 116$ & $39.1^{*}$ \\
\hline & $91.281-4$ & $31 \pm 9$ & $1,055 \pm 308$ & $2,132^{* *} \pm 102$ & $1,834^{*} \pm 102$ & $13.6^{*}$ \\
\hline \multirow[t]{10}{*}{1996} & Mean squares & 27,940 & $16,440,000$ & $127,462^{*}$ & 134,261 & \\
\hline & Chandler & $299 \pm 76$ & $10,568 \pm 4,465$ & $1,358 \pm 80$ & $1,087 \pm 122$ & 19.2 \\
\hline & Cuesta & $481 \pm 4$ & $14,134 \pm 2,968$ & $1,318 \pm 102$ & $776 \pm 20$ & 40.9 \\
\hline & Camarosa & $340 \pm 167$ & $8,640 \pm 3,968$ & $1,790^{*} \pm 29$ & $1,555^{*} \pm 155$ & 13.3 \\
\hline & C204 & $523 \pm 38$ & $11,364 \pm 1,864$ & $1,604 \pm 44$ & $1,192 \pm 178$ & 25.3 \\
\hline & Gaviota & $121 \pm 41$ & $3,602 \pm 1,574$ & $1,302 \pm 141$ & $1,187 \pm 47$ & 7.3 \\
\hline & C206 & $384 \pm 26$ & $10,235 \pm 953$ & $986 \pm 5$ & $661 \pm 123$ & $32.9^{*}$ \\
\hline & $\mathrm{C} 207$ & $327 \pm 91$ & $8,528 \pm 419$ & $1,685 \pm 265$ & $1,086 \pm 303$ & 36.8 \\
\hline & $92.63-2$ & $240 \pm 175$ & $7,841 \pm 5,356$ & $1,528 \pm 85$ & $930 \pm 12$ & 38.9 \\
\hline & $92.291-3$ & $266 \pm 122$ & $9,098 \pm 4,445$ & $1,675 \pm 133$ & $1,064 \pm 231$ & 37.1 \\
\hline
\end{tabular}

ㄱairwise $t$ tests were calculated within year to determine if the mean of each genotype was significantly different from the mean of 'Chandler.'

yPairwise $t$ tests were calculated within year and genotype for yield between acaricide treated and nontreated plots to determine if the percentage of yield reduction caused by $T$. urticae feeding was significant.

*,** Significant (or significantly different from the mean of 'Chandler') at $P<0.05$ or 0.01 , respectively. 
Table 2. ANOVA for day-neutral genotypes tested within year, and mean and SE for maximum abundance of $T$. urticae observed per leaflet, accumulated mite-days in nonacaricide treated plots, yield in acaricide-treated and nontreated plots, and yield reduction caused by T. urticae feeding.

\begin{tabular}{|c|c|c|c|c|c|c|}
\hline \multirow[b]{2}{*}{ Year } & \multirow[b]{2}{*}{ Genotype } & \multirow{2}{*}{$\begin{array}{c}\text { T. urticael } \\
\text { leaflet }^{\mathrm{z}}\end{array}$} & \multirow{2}{*}{$\begin{array}{l}\text { Mite- } \\
\text { days }^{\mathrm{z}}\end{array}$} & \multicolumn{2}{|c|}{ Yield (g/plant) ${ }^{2}$} & \multirow{2}{*}{$\begin{array}{c}\text { Yield } \\
\text { reduction }(\%)\end{array}$} \\
\hline & & & & Treated & Nontreated & \\
\hline \multirow[t]{9}{*}{1989} & Mean squares & 333 & 822,288 & $442,837^{* *}$ & $260,895^{* * *}$ & \\
\hline & Selva & $72 \pm 1$ & $2,560 \pm 840$ & $2,292 \pm 156$ & $1,262 \pm 16$ & $44.6^{*}$ \\
\hline & Muir & $81 \pm 32$ & $2,908 \pm 1,390$ & $1,985^{*} \pm 139$ & $1,089 \pm 31$ & $45.0^{*}$ \\
\hline & Oso Grande & $51 \pm 12$ & $2,536 \pm 254$ & $2,000 \pm 29$ & $1,108 \pm 137$ & $44.5^{*}$ \\
\hline & Seascape & $83 \pm 23$ & $3,759 \pm 1,044$ & $2,397 \pm 80$ & $1,878^{* *} \pm 182$ & 21.8 \\
\hline & Capitola & $80 \pm 32$ & $3,889 \pm 365$ & $3,306^{* *} \pm 37$ & $1,922 \pm 37$ & $41.9^{*}$ \\
\hline & $85.19-29$ & $64 \pm 6$ & $3,083 \pm 481$ & $3,018^{* * *} \pm 5$ & $1,626^{* *} \pm 118$ & $46.1^{*}$ \\
\hline & Sunset & $86 \pm 5$ & $4,235 \pm 431$ & $544 \pm 103$ & $1,278 \pm 8$ & $46.6^{* *}$ \\
\hline & $85.190-2$ & $91 \pm 77$ & $2,917 \pm 2,194$ & $2,240 \pm 70$ & $1,885^{* *} \pm 66$ & 15.8 \\
\hline \multirow[t]{8}{*}{1991} & Mean squares & 379 & 204,587 & $109,984^{* * *}$ & $181,648^{*}$ & \\
\hline & Selva & $42 \pm 11$ & $907 \pm 230$ & $1,410 \pm 32$ & $1,116 \pm 184$ & 20.6 \\
\hline & Irvine & $29 \pm 20$ & $788 \pm 466$ & $1,176^{*} \pm 71$ & $963 \pm 97$ & 18.3 \\
\hline & Seascape & $26 \pm 15$ & $662 \pm 364$ & $1,542^{*} \pm 29$ & $1,429^{*} \pm 248$ & 7 \\
\hline & Capitola & $11 \pm 4$ & $306 \pm 74$ & $2,159^{* *} \pm 48$ & $1,791^{*} \pm 204$ & 17.2 \\
\hline & Sunset & $7 \pm 3$ & $152 \pm 72$ & $1,672^{*} \pm 105$ & $1,698^{*} \pm 6$ & -2 \\
\hline & $87.112-10$ & $10 \pm 9$ & $367 \pm 363$ & $1,642 * \pm 62$ & $1,398 \pm 60$ & 14.9 \\
\hline & $87.153-2$ & $6 \pm 5$ & $87 \pm 69$ & $1,800^{* *} \pm 9$ & $1,588^{*} \pm 76$ & 11.8 \\
\hline \multirow[t]{6}{*}{1992} & Mean squares & 15,020 & $8,749,963$ & $414,250^{* * *}$ & $229,502^{* *}$ & \\
\hline & Selva & $291 \pm 34$ & $11,940 \pm 2,755$ & $1,029 \pm 55$ & $412 \pm 1$ & $59.8^{* *}$ \\
\hline & Seascape & $324 \pm 162$ & $5,617 \pm 1,741$ & $1,743^{* *} \pm 46$ & $979^{* *} \pm 119$ & $43.6^{*}$ \\
\hline & Sunset & $247 \pm 120$ & $4,779^{*} \pm 1,311$ & $2,309^{* *} \pm 66$ & $1,346^{* *} \pm 8$ & $41.7^{* *}$ \\
\hline & $87.107-4$ & $150 \pm 62$ & $3,210^{*} \pm 994$ & $1,622^{* * *} \pm 5$ & $1,057^{* *} \pm 1$ & $34.8^{* *}$ \\
\hline & $87.291-202$ & $126 \pm 80$ & $2,936^{*} \pm 1,550$ & $1,711^{* *} \pm 149$ & $923^{* *} \pm 104$ & $46.1^{*}$ \\
\hline \multirow[t]{7}{*}{1993} & Mean squares & 23,051 & $9,467,967$ & $273,640^{* * *}$ & $394,863^{* *}$ & \\
\hline & Selva & $337 \pm 242$ & $6,768 \pm 3,914$ & $999 \pm 32$ & $638 \pm 186$ & 39.7 \\
\hline & Seascape & $217 \pm 40$ & $5,058 \pm 1,476$ & $1,225 \pm 4$ & $994 \pm 10$ & $18.8^{* *}$ \\
\hline & Sunset & $129 \pm 87$ & $3,004 \pm 1,814$ & $1,330^{*} \pm 6$ & $1,231 \pm 45$ & 7.5 \\
\hline & $89.206-2$ & $182 \pm 14$ & $6,121 \pm 40$ & $592^{* *} \pm 2$ & $313 \pm 54$ & $47.1^{*}$ \\
\hline & $89.250-31$ & $244 \pm 98$ & $5,204 \pm 2,774$ & $1,615^{* *} \pm 233$ & $1,585 \pm 162$ & 1.3 \\
\hline & $90.280-1$ & $20 \pm 0$ & $915 \pm 117$ & $814 \pm 33$ & $944 \pm 59$ & 16.5 \\
\hline \multirow[t]{7}{*}{1994} & Mean squares & 5,061 & $6,791,104$ & 237,984 & $171,889^{* * *}$ & \\
\hline & Selva & $230 \pm 20$ & $5,212 \pm 153$ & $1,552 \pm 95$ & $1,576 \pm 95$ & -1.2 \\
\hline & Seascape & $178 \pm 32$ & $5,359 \pm 1,311$ & $1,721 \pm 135$ & $1,560 \pm 135$ & 8.8 \\
\hline & Sunset & $88 \pm 76$ & $3,232 \pm 2,824$ & $1,647 \pm 49$ & $1,390 \pm 49$ & 15.1 \\
\hline & $89.218-31$ & $160 \pm 37$ & $4,334 \pm 1,252$ & $1,861 \pm 346$ & $1,512 \pm 346$ & 14.4 \\
\hline & $90.275-1$ & $163 \pm 22$ & $4,010 \pm 1$ & $925 \pm 25$ & $797^{* *} \pm 25$ & 13.9 \\
\hline & $90.276-2$ & $216 \pm 22$ & $5,149 \pm 648$ & $1,829 \pm 127$ & $1,312 \pm 127$ & 28.2 \\
\hline \multirow[t]{6}{*}{1995} & Mean squares & 1,275 & 847,898 & $56,835^{*}$ & 11,090 & \\
\hline & Selva & $85 \pm 22$ & $2,230 \pm 288$ & $1,438 \pm 85$ & $1,214 \pm 291$ & 14.1 \\
\hline & Seascape & $53 \pm 35$ & $2,221 \pm 1,655$ & $1,328 \pm 8$ & $1,087 \pm 250$ & 18.3 \\
\hline & Sunset & $62 \pm 7$ & $1,814 \pm 263$ & $1,700^{*} \pm 73$ & $1,290 \pm 72$ & 23.8 \\
\hline & $89.218-31$ & $114 \pm 66$ & $3,462 \pm 2,170$ & $1,587 \pm 5$ & $1,206 \pm 10$ & $24.0^{*}$ \\
\hline & Aromas & $58 \pm 14$ & $1,976 \pm 1,040$ & $1,719^{*} \pm 76$ & $1,236 \pm 109$ & 27.6 \\
\hline \multirow[t]{10}{*}{1996} & Mean squares & 32,117 & $18,850,000$ & 56,885 & 62,065 & \\
\hline & Selva & $404 \pm 76$ & $11,687 \pm 1,699$ & $1,312 \pm 56$ & $913 \pm 30$ & $30.2^{*}$ \\
\hline & Seascape & $456 \pm 192$ & $10,165 \pm 3,038$ & $1,517 \pm 124$ & $1,139 \pm 82$ & 23.9 \\
\hline & Sunset & $462 \pm 198$ & $11,789 \pm 2,842$ & $1,625 \pm 170$ & $1,249 \pm 76$ & 21.8 \\
\hline & $90.248-1$ & $258 \pm 60$ & $7,730 \pm 1,560$ & $1,415 \pm 92$ & $1,175 \pm 26$ & 16.5 \\
\hline & Aromas & $188 \pm 26^{*}$ & $5,285^{*} \pm 226$ & $1,703^{*} \pm 75$ & $1,376 \pm 121$ & 18.8 \\
\hline & Diamante & $201 \pm 8^{*}$ & $5,516^{*} \pm 357$ & $1,692^{*} \pm 48$ & $1,372 \pm 116$ & 19 \\
\hline & $91.256-5$ & $380 \pm 114$ & $9,425 \pm 1,301$ & $1,328 \pm 24$ & $929 \pm 174$ & 29.7 \\
\hline & Pacific & $400 \pm 109$ & $9,552 \pm 365$ & $1,277 \pm 9$ & $990 \pm 177$ & 22.4 \\
\hline & $92.289-4$ & $127 \pm 98$ & $3,033^{* *} \pm 2,316$ & $1,358 \pm 154$ & $1,051 \pm 8$ & 21.5 \\
\hline
\end{tabular}

${ }^{2}$ Pairwise $t$ tests were calculated within year to determine the mean of each genotype was significantly different from the mean of 'Selva.'

yPairwise $t$ tests were calculated within year and genotype for yield between acaricide treated and nontreated plots to determine if the percentage of yield reduction caused by $T$. urticae feeding was significant.

${ }^{*}, * *$ Significant (or significantly different from the mean of 'Selva') at $P<0.05$ or 0.01 , respectively. 
Table 3. Results of ANOVA for yield (March through August) and fruit size (May and June) for strawberry genotypes.

\begin{tabular}{|c|c|c|c|c|c|c|c|c|c|}
\hline \multirow[b]{3}{*}{ Source } & \multicolumn{9}{|c|}{ Mean squares ${ }^{z}$} \\
\hline & \multicolumn{3}{|c|}{$\begin{array}{l}\text { Short-day genotypes } \\
\text { (replicate year), } \mathrm{n}=174\end{array}$} & \multicolumn{3}{|c|}{$\begin{array}{l}\text { Day-neutral genotypes } \\
\text { (replicate year), } \mathrm{n}=182\end{array}$} & \multicolumn{3}{|c|}{$\begin{array}{c}\text { All genotypes } \\
\text { (replicate year combined) } \mathrm{n}=356\end{array}$} \\
\hline & $\mathrm{df}$ & Yield & Fruit size & df & Yield & Fruit size & df & Yield & Fruit size \\
\hline Year & 6 & $281,237^{* *}$ & $82.64^{* *}$ & 6 & $928,627^{* *}$ & $60.29^{* * *}$ & 6 & $1,210,463^{* *}$ & $159.17^{* * *}$ \\
\hline Replicate (year) & 7 & 45,817 & 4.79 & 7 & 42,938 & 3.29 & 7 & 47,068 & $7.05^{* * *}$ \\
\hline Genotype & 23 & $539,354^{* * *}$ & $56.26^{* *}$ & 24 & $432,248^{* * *}$ & $52.66^{* *}$ & 46 & $542,948^{* *}$ & $71.52^{* *}$ \\
\hline Spray & 1 & $8,817,172^{* *}$ & $53.52^{* *}$ & 1 & $5,228,480^{* *}$ & $38.93^{* *}$ & 1 & $13,621,961^{* *}$ & $90.44^{* *}$ \\
\hline Year genotype & 14 & $56,618^{* *}$ & 3.24 & 14 & $135,620^{* * *}$ & $3.74^{*}$ & 35 & $102,018^{* *}$ & $5.16^{* *}$ \\
\hline Year spray & 6 & $124,815^{* *}$ & $10.45^{* *}$ & 6 & $289,719^{* *}$ & $4.65^{* *}$ & 6 & $406,526^{* *}$ & $4.93^{*}$ \\
\hline Genotype spray & 23 & $83,963^{* *}$ & 2.38 & 23 & 42,030 & $3.01^{\mathrm{NS}}$ & 46 & $67,472^{* *}$ & 3.44 \\
\hline Year genotype spray & 13 & $17,967^{\mathrm{Ns}}$ & 1.87 & 14 & 42,627 & 2.63 & 35 & $38,290^{*}$ & 3.52 \\
\hline Error & 80 & 23,193 & 2.15 & 86 & 26,493 & 2.03 & 173 & 25,557 & 2.07 \\
\hline$\sigma^{2} \mathrm{G}$ & & $65,269(75.6)$ & $8.29(95.8)$ & & 47,701 (85.8) & $7.71(94.8)$ & & $43,605(81.7)$ & $9.47(92.9)$ \\
\hline$\sigma^{2} \mathrm{GS}$ & & $21,082(24.4)$ & $0.36(4.2)$ & & $0(0)$ & $0.12(1.5)$ & & $5,518(10.3)$ & $0.00(0)$ \\
\hline$\sigma^{2} \mathrm{GSY}$ & & $0(0)$ & $0.00(0)$ & & $7,922(14.2)$ & $0.30(3.7)$ & & $4,271(8.0)$ & $0.72(7.1)$ \\
\hline
\end{tabular}

${ }^{\mathrm{z}}$ Variance component values labeled 0 were small and negative; values in parentheses are percentages of the total phenotypic variance of random effect $\sigma^{2} ; \mathrm{G}=$ genotype; $\mathrm{S}=$ spray; and $\mathrm{Y}=$ year.

**** Significant at $P<0.05$ or 0.01 , respectively.

\section{Discussion}

Pest resistance is only one facet of the selection process in development of new strawberry cultivars for commercial fruit production. To become commercially successful, a cultivar must express a large number of desirable horticultural traits. Principally, the plant must have the genetic potential to produce a high volume of large, visually attractive, firm fruit over a relatively extended time period. It must be adaptable to a range of microclimates, and the plant must be compact with a relatively open canopy to facilitate hand harvesting. We began our studies in 1988 following removal of cyhexatin (Plictran 50W; Du Pont, Wilmington, Del.) from use for mite control on all commodities. California strawberry producers had used cyhexatin to suppress T. urticae infestations, and cancellation of the registration left strawberry producers with very few mite control options. Additionally, the strawberry industry was experiencing a rapid expansion in hectares. In 1980, there were 4,452 ha of strawberries in California that yielded 159,622 $\mathrm{t}$ of fresh market strawberries. By
1990, there were 8,073 ha that yielded 303,241 t, and in 1996, there were 10,217 ha that produced 402,908 t. The 1983 release of the cultivars, Selva and Chandler, contributed to this rapid expansion in fresh-market fruit volume. The release of 'Selva' in particular resulted in substantial changes in cultural practices and fruit production patterns in the central California coast growing districts. Before release of 'Selva,' strawberries were typically summer transplanted (August or early September) as frigo plants (transplants that had been harvested from low-elevation Sacramento Valley nurseries the previous winter and kept in cold storage at $-2.2^{\circ} \mathrm{C}$ ). Selva is fall transplanted (November or early December) as a fresh plant from high-elevation nurseries. Initial University of California recommendations for the length of supplemental cold storage required to promote adequate plant vigor for 'Selva' before transplant was $10 \mathrm{~d}$.

Current recommendations call for at least 2 weeks supplemental cold storage (Welch 1990, Walsh et al., 1997), and many producers will store their plants for 4 weeks or longer before transplant. 'Selva' transplanted with only $10 \mathrm{~d}$ of cold storage

Table 4. Path analysis of phenotypic correlations for direct effects (underlined) and indirect effects of week T. urticae became detectable, and monthly interval of mite-day (MD) accumulation (April through August) on the yield of short-day, and day-neutral, strawberry genotypes.

\begin{tabular}{|c|c|c|c|c|c|c|c|}
\hline \multirow[b]{2}{*}{ Genotype } & \multirow{2}{*}{$\begin{array}{c}\text { Week } \\
\text { T. urticae } \\
\text { detected }\end{array}$} & \multicolumn{6}{|c|}{ MD accumulation during } \\
\hline & & April & May & June & July & August & Yield \\
\hline \multicolumn{8}{|c|}{ Short-day $\left(r^{2}=0.222\right)$} \\
\hline Week detected & $\underline{0.042}$ & -0.083 & -0.036 & -0.034 & -0.009 & -0.011 & -0.130 \\
\hline MD April & $-\overline{-0.029}$ & $\underline{0.120}$ & 0.037 & -0.027 & 0.007 & -0.011 & 0.098 \\
\hline MD May & -0.026 & $\overline{0.075}$ & $\underline{0.059}$ & 0.136 & 0.004 & 0.064 & 0.313 \\
\hline MD June & -0.004 & -0.009 & 0.023 & $\underline{0.346}$ & -0.012 & 0.080 & 0.425 \\
\hline MD July & 0.014 & -0.033 & -0.008 & 0.160 & -0.026 & 0.015 & 0.122 \\
\hline MD August & -0.003 & -0.008 & 0.024 & 0.179 & -0.002 & $\underline{0.156}$ & 0.345 \\
\hline \multicolumn{8}{|c|}{ Day-neutral $\left(r^{2}=0.237\right)$} \\
\hline Week detected & -0.473 & -0.207 & -0.380 & -0.056 & -0.024 & -0.021 & -0.352 \\
\hline MD April & 0.225 & $\underline{0.435}$ & -0.318 & -0.020 & -0.011 & -0.010 & 0.341 \\
\hline MD May & 0.365 & 0.281 & $\underline{0.492}$ & 0.082 & -0.029 & 0.013 & 0.220 \\
\hline MD June & 0.163 & 0.053 & 0.250 & $\underline{0.161}$ & 0.008 & -0.001 & 0.136 \\
\hline MD July & -0.175 & -0.073 & 0.218 & 0.019 & $\underline{0.066}$ & -0.065 & -0.010 \\
\hline MD August & -0.082 & 0.370 & 0.550 & 0.001 & 0.036 & $\underline{0.119}$ & 0.072 \\
\hline
\end{tabular}


lacks vigor and is more susceptible to early infestation by $T$. urticae (Walsh et al., 1997). Under growing conditions of low plant vigor that was typical during the 1980s, 'Selva' was perceived as more susceptible to $T$. urticae infestation than the older summer-planted, short-day cultivars it replaced. However, 'Selva' was planted because of the production advantages it offered as a day-neutral genotype. These include adaptability to fall transplanting (the plants are in the ground less time than summertransplant, resulting in a reduction of production costs), earlier fruiting than summer planted short-day cultivars, and fruit production in continuous cycles from mid-spring through fall. In addition, the fruit of 'Selva' is firm and ships well to market (Welch, 1990), whereas the fruit from the summer planted cultivars 'Selva' replaced, softened late season making the fruit more susceptible to various rots (Bringhurst, 1981).

During the late 1980s, 'Chandler' replaced most cultivars grown previously in southern California. Because 'Selva' began producing fruit earlier and for a substantially longer period of time in the central coast growing districts than the cultivars it replaced, southern California strawberry producers experienced a shrinkage of their market window in spring. This resulted in southern California strawberry producers focusing their plant culture towards fruit production by 'Chandler' for a substantially earlier market window in January and February. This was accomplished by harvesting the nursery transplants and establishing production plantations earlier in October, resulting in less plant chilling before establishment. Reduced plant chilling resulted in plants with less vigor (Voth and Bringhurst, 1970) and increased plant susceptibility to mites (Walsh et al., 1997). Therefore, strawberry producers perception that the cultivars Selva and Chandler are more susceptible to infestation by $T$. urticae than other cultivars is unsubstantiated by our study and is perhaps more a result of the shift in cultural practices caused by economic and market forces than of cultivar susceptibility.

The present investigation demonstrates that $T$. urticae feeding resulted in substantial yield reductions regardless of genotype within the University of California advanced-cycle breeding population. There were differences in yield response between day-neutral genotypes and short-day genotypes, but the environmental effect of pretransplant supplemental cold storage that differed between the two plant types makes direct comparison difficult and will require further study. Distribution of variance between G, GS, and GSY imply there is little variability for mite resistance among day-neutral genotypes (Table 3 ). The greatest economic gain, in terms of cultivars for use in the central coast growing districts of California, will be realized by breeding for more efficient production and increased yield. However, some gains in genotypic mite resistance may be realized for short-day genotypes for southern California strawberry producers who grow short-day cultivars using cultural practices that involve few opportunities to promote plant vigor through the traditional plant chilling response.

The path coefficient analysis reveals differences between the two photoperiodic plant types in yield pattern and yield reduction due to $T$. urticae feeding (Table 4). On average, short-day genotypes that had been treated with acaricides produced $55.4 \%$ of their fruit by 31 May. In contrast, day-neutral genotypes treated with acaricides on average had only produced $42.0 \%$ of their total seasonal yield by 31 May, though total average seasonal yields for all 7 years of this study were about equivalent (at 1,601 g/plant for short-day genotypes and $1,667 \mathrm{~g} /$ plant for day-neutral genotypes) when $T$. urticae remained suppressed. Following the peak fruit- ing period of May and June, we observed that short-day genotypes that were damaged by $T$. urticae feeding in June appeared to undergo a vegetative growth period in July, whereas plants that had not sustained $T$. urticae feeding continued to produce strawberries, though at a much reduced rate of production compared with May and June. Yield reduction due to mite feeding averaged $40 \%$ on short-day genotypes in July, and this was the highest monthly yield loss for short-day genotypes. This is explained by the strong direct effect on yield from mite-days accumulated during June. Day-neutral genotypes appear to have a more complex yield response to $T$. urticae feeding, likely due to their more complicated fruiting pattern. The additional supplemental cold storage before transplant that the day-neutral genotypes received did delay peak fruiting. However, the day-neutral genotypes also appeared to be very sensitive to early season (before June) mite feeding.

Differences in flowering responses between day-neutral genotypes and short-day genotypes may explain the differences in yield response to T. urticae feeding. For short-day genotypes in California, floral bud differentiation terminates in spring, after which the plant's yield potential is predetermined (Larson, 1994). Alternatively, it appears that day-neutral genotypes are capable of floral bud initiation at all mild temperatures regardless of daylength (Durner and Poling, 1987). These patterns may explain the response of the short-day genotypes to $T$. urticae feeding that is manifested as an abrupt reduction of fruiting in June and July following plant stress due to T. urticae feeding. However, the day-neutral genotypes are more sensitive to early season miteday accumulations in that mite-day accumulations during April and May have the greatest direct effect on yield. We speculate that day-neutral genotypes continue to initiate floral buds during spring and that this may explain their responses to $T$. urticae feeding. Additionally, we have observed that day-neutral genotypes that have experienced substantial $T$. urticae infestations in spring can recover and will produce fruit later in summer; these plants can never recover lost yield, but they do resume fruiting. Once damaged by $T$. urticae feeding in spring, short-day cultivars rarely produce marketable fruit in late summer.

The University of California strawberry improvement program continues to release new cultivars. 'Chandler' was planted on 4,605 ha in California in 1993, but was being grown on only 431 ha by the 1996-97 season (California Strawberry Commission, 2001). 'Camarosa' has replaced 'Chandler' entirely (California Strawberry Commission, 2001). In pairwise comparisons between 'Chandler' and 'Camarosa' conducted in 1992, 1994, 1995, and 1996, 'Camarosa' had substantially higher yields than 'Chandler' when $T$. urticae populations remained suppressed (Table 1). Unfortunately, 'Camarosa' is susceptible to T. urticae feeding and had a greater percentage of yield reduction than 'Chandler' in 3 of 4 years. In 1995 (a moderate T. urticae infestation year), and 1996 (a high T. urticae infestation year), plants from the nonacaricide treated 'Camarosa' plots had higher yields than the 'Chandler' plants from plots on which $T$. urticae populations were suppressed (Table 1). We observed similar trends in 1996, between 'Selva' and 'Diamante' and to a lesser degree 'Aromas', two of the University of California's recently released day-neutral cultivars. Both new cultivars yielded significantly $(P<0.05)$ more fruit when $T$. urticae populations remained suppressed, and even when subjected to over 5,000 cumulative mite-days over the season, had yields that were not statistically different from those of the acaricide-treated 'Selva' plants (Table 2 ). Although the variance components indicated there is little 
opportunity for substantial and rapid genetic improvement in mite resistance among the genotypes tested in this population (Table 4), the tendency of new cultivars to have high yields in the presence or absence of $T$. urticae feeding achieves, in part, the goal of pest resistance.

\section{Literature Cited}

Abacus Concepts. 1989. Super ANOVA. Abacus Concepts, Berkeley, Calif.

Andrews, K.L. and L. LaPre. 1979. Effect of Pacific mite on physiological processes of almond foliage. J. Econ. Entomol. 72:651-654.

Barritt, B.H. 1980. Breeding for resistance to insects and mites, p. 201213. In: N.F. Childers (ed.). The strawberry: Cultivars to marketing. Hort. Publ., Gainesville, Fla.

Bringhurst, R.S. 1981. Strawberry production trends in the western USA, p. 13-21. In: N.F. Childers (ed.). The strawberry: Cultivars to marketing. Hort. Publ., Gainesville, Fla.

California Department of Pesticide Regulation. 1999. Pesticide use report, 1998. Calif. Dept. Pesticide Regulat., Sacramento.

California Strawberry Commission. 2001. Survey of California strawberry acreage. Calif. Strawberry Comm., Watsonville 1(6).

Durner, E.F. and E.B. Poling. 1987. Flower bud induction, initiation, differentiation and development in the 'Earliglow' strawberry. Sci. Hort. 31:61-69.

Fisher, R.A. and F. Yates. 1949. Statistical tables for biological, agricultural, and medical research. 2nd ed. Hafner, New York.

Galletta, G.J. and R.S. Bringhurst. 1990. Strawberry management, p. 83 156. In: G.A. Galleta and D.G. Himelrick (eds.). Small fruit crop management. Prentice Hall, Englewood Cliffs, N.J.

Gimenez-Ferrer, R.M.G., J.C. Scheerens, and W.A. Erb. 1993. In vitro screening of 76 strawberry cultivars for two-spotted spider mite resistance. HortScience 28:841-844.

Hancock, J.F., J.L. Mass, C.H. Shanks, P.J. Breen, and J.J. Luby. 1990. Strawberries (Fragaria), p. 491-546. In: J.N. Moore and J.R. Ballington (eds.). Genetic resources of temperate fruit and nut crops. Intl. Soc.
Hort. Sci., Wageningen, The Netherlands.

Henderson, C.F. and H.V. McBurnie. 1954. Sampling techniques for determining populations of citrus red mite and its predators. USDA Circ. 671.

Jurik, J.W. 1985. Differential costs of sexual and vegetative reproduction in wild strawberry populations. Oecologia 66:394-403.

Larson K.D. 1994. Strawberry, p. 271-297. In: B. Schaffer and P.C. Anderson (eds.). Handbook of environmental physiology of fruit crops. Univ. Fla. Press, Gainesville.

Li, C.C. 1975. Path analysis-A primer. Boxwood Press, Pacific Grove, Calif.

Loehlin, J.C. 1987. Latent variable models: An introduction to factor, path, and structural analysis. L. Earlbaum Assoc., Hillsdale, N.J.

SAS Institute, Inc. 1990. SAS/STAT user's guide, release 6.04. SAS Inst. Inc., Cary, N.C.

Shanks, C.H. 1980. Insects and mites, p. 293-308. In: N.F. Childers (ed.). The strawberry: Cultivars to marketing. Hort. Publ., Gainsville, Fla.

Shanks, C.H. and P.P. Moore. 1995. Resistance to two-spotted spider mite and strawberry aphid in Fragaria chiloensis, $F$. Virginiana, and F. Xananassa clones. HortScience 30:596-599.

Voth, V. and R.S. Bringhurst. 1970. Influence of nursery harvest date, cold storage, and planting date on performance of winter planted California strawberries. J. Amer. Soc. Hort. Sci. 95:496-500.

Walsh, D.B., F.G. Zalom, N.C. Welch, C. Pickel, and D.V. Shaw. 1997. Pre-transplant cold storage of strawberries: Effects on plant vigor, yield, and spider mite (Acari: Tetranychidae) abundance. J. Economic Entomol. 90:818-823.

Welch, N.C. 1990. Strawberry production in California. Univ. Calif. Div. Agr. Nat. Resources Publ. 2959.

Wright, S. 1921. Correlation and causation. J. Agr. Res. 20:557-585.

Zalom, F.G., C. Pickel, and N.C. Welch. 1990. Recent trends in strawberry arthropod management for coastal areas of the western United States, p. 239-259. In: N.J. Bostonian, L.T. Wilson, and T.J. Dennehy (eds.). Monitoring and integrated management of arthropod pests of small fruit crops. Intercept, Andover, N.H. 